\title{
AVIAN INFLUENZA A (H5N1) IN BANGLADESH
}

Over the past one year, people of Bangladesh became familiar with the term "bird flu" if not avian influenza. The latter terminology became a buzz word in the literate circle and $\mathrm{H} 5 \mathrm{~N} 1$ virus was a much talked about topic amongst the medical scientists and public health specialists.

The reasons were obvious. News papers reported authoritative sources saying that 152 poultry farms in 47 districts (out of 64) detected presence of bird flu. Hundreds of thousands of chickens were culled by February 2008. People were reluctant to consume chicken as well as eggs and consumption dropped more than $50 \%$. Losses of Taka 5000 crore or more were estimated. With the advent of summer, the threat of the flu petered out but the farm owners were reluctant to invest in a fresh start fearing a return of the virus. This was particularly so for the 'layers' which take a longer time to raise. As a consequence, the price of eggs continued to be higher than usual. The overall effect of this was a compromise in the diet, particularly for the children. Their diet remained protein void resulting in a further lowering of their already compromised nutritional status.

Avian influenza, or "bird flu", also called "H5N1 virus" - is an influenza A virus subtype that occurs mainly in birds, being highly contagious (among birds), and deadly to them. H5N1 virus does not usually infect people, but infections with these viruses have occurred in humans. Most of these cases have resulted from people having direct or close contact with H5N1infected poultry. Influenza viruses are grouped into three types, designated A, B, and C. Only influenza A viruses can cause pandemics. Influenza $A$ viruses have $16 \mathrm{H}$ subtypes and $9 \mathrm{~N}$ subtypes. Only some of the viruses of the $\mathrm{H} 5$ and $\mathrm{H} 7$ subtypes are known to cause the highly pathogenic form of the disease.

The current outbreaks of highly pathogenic avian influenza, which began in South-East Asia in mid2003, are the largest and most severe on record. Never before in the history of this disease have so many countries been simultaneously affected, resulting in the loss of so many birds. The causative agent, the $\mathrm{H} 5 \mathrm{~N} 1$ virus, has proved to be especially tenacious. Despite the death or destruction of an estimated 150 million birds, the virus is now considered endemic in many parts of Indonesia and Viet Nam and in some parts of Cambodia, China, Thailand, and possibly Laos. Control of the disease in poultry is expected to take several years.

The widespread persistence of $\mathrm{H} 5 \mathrm{~N} 1$ in poultry populations poses two main risks for human health. The first is the risk of direct infection when the virus passes from poultry to humans, resulting in very severe disease. Of the few avian influenza viruses that have crossed the species barrier to infect humans, H5N1 has caused the largest number of cases of severe disease and death in humans. A second risk, of even greater concern, is that the virus - if given enough opportunities - will change into a form that is highly infectious for humans and spreads easily from person to person. Such a change could mark the start of a global outbreak (a pandemic).

Direct contact with infected poultry, or surfaces and objects contaminated by their faeces, is presently considered the main route of human infection. To date, most human cases have occurred in rural or periurban areas where many households keep small poultry flocks, which often roam freely, sometimes entering homes or sharing outdoor areas where children play. As many households in Asia depend on poultry for income and food, many families sell or slaughter and consume birds when signs of illness appear in a flock, and this practice has proved difficult to change. Exposure is considered most likely during slaughter, defeathering, butchering, and preparation of poultry for cooking.

An important public health issue has been, whether we should advice people to continue consuming chicken. The Government of Bangladesh is rightly promoting the safety in consumption of poultry and eggs. However, certain precautions should be followed. In areas free of the disease, poultry and poultry products can be prepared and consumed as usual with no fear of acquiring infection with the $\mathrm{H} 5 \mathrm{~N} 1$ virus. In areas experiencing outbreaks, poultry and poultry products can also be safely consumed provided these items are properly cooked and properly handled during food preparation. The $\mathrm{H} 5 \mathrm{~N} 1$ virus is sensitive to heat. Normal temperatures used for cooking $\left(70^{\circ} \mathrm{C}\right.$ in all parts of the food) will kill the virus. Consumers need to be sure that all parts of the poultry are fully cooked 
(no "pink" parts) and that eggs, too, are properly cooked (no "runny" yolks). Avian influenza is not transmitted through cooked food. To date, no evidence indicates that anyone has become infected following the consumption of properly cooked poultry or poultry products, even when these foods were contaminated with the $\mathrm{H} 5 \mathrm{~N} 1$ virus.

The first and only human case in Bangladesh was reported in a 16 month old child. The onset was estimated to be on the $22^{\text {nd }}$ of January, 2008. A chicken was bought from a nearby retail poultry shop who in turn imported it from a HPAI H5N1 endemic area despite a ban on inter district movement of poultry. The child reportedly played with the live chicken before being slaughtered by the child's mother. The child was detected with the virus as a part of the population based surveillance on H5N1 in urban Dhaka (Kamlapur) and later confirmed from CDC, Atlanta. Luckily the child survived.
The H5N1 virus that has caused human illness and death in Asia is resistant to amantadine and rimantadine, two antiviral medications commonly used for influenza. Two other antiviral medications, oseltamivir (commercially known as Tamiflu) and zanamivir (commercially known as Relenza) would probably work to treat influenza caused by $\mathrm{H} 5 \mathrm{~N} 1$ virus, but additional studies still need to be done to demonstrate their effectiveness. Preventive measures, including modernization of poultry farms with support from Government, and creating awareness amongst the masses should go a long way in tackling this grave situation.

\section{Prof. Mamunar Rashid}

Professor \& Head

Department of Community Medicine

Ibrahim Medical College 